tion. Simultaneously, because of the low quality of primary and secondary education in Ethiopia, students are unprepared for university-level education. The country's Fifth Education Sector Development Program (ESDP V) reported that "many students joined higher education institutions with results below the 50 percent threshold in the higher education entrance examinations." ESDP V further notes that the combination of low-quality instruction and unprepared students could be the cause for low graduation rates among undergraduate students. For the government, on the one hand, to make such an assessment, and, on the other hand, to hire university teachers with such poor levels of academic performance appears to be utterly self-defeating.

The problem is even more serious in certain fields. For example, the average score for test takers in the fields of mathematics and physics were 48.3 and 50.5, respectively. Such low scores in these fields are particularly worrisome, since these subjects are considered fundamental to the country's priority academic areas of engineering, science, and technology.

There are also implications for research capacity. Since 2OII-2OI2, research has accounted for only I percent of the total budget of all universities, and much of the research is conducted predominantly by graduate students. Given the quality of graduates, and of those admitted into graduate programs, the research capacity of Ethiopian universities is in serious jeopardy.

\section{What Can Be Done?}

The overall poor quality of Ethiopian university education, its graduates, and its research infrastructure represents a real danger to the national economy and the country's development agenda. Immediate responses are needed to address these concerns.

As a quick fix, there is a need to create arrangements for competent professionals from industry to take part in teaching, perhaps partnering with freshly graduated assistant recruits; establishing a mentorship program where senior staff could train and empower their novice colleagues; creating better pay and benefits packages that attract more qualified professionals to the teaching profession; better utilizing Ethiopian professionals in the diaspora; and, in spite of all its drawbacks, using expatriates in certain important fields.

The long-term solution is, however, to slow down expansion and focus on strengthening existing institutions, with particular emphasis on creating differentiation across the system. Specifically, by reducing the rate at which new universities are established, selected senior institutions must be elevated to research universities and resourced accordingly. These institutions can engage in high level academic and research work, which provides two key benefits.
First, they will serve as hubs for knowledge generation and transfer, and for scientific and technological advancement. This provides the critically needed knowledge supply for the development of key sectors, such as agriculture and industry. Second, as epicenters of academic advancement, they will have the capacity to strategically produce highly trained and qualified academic staff for the new universities to be established, and strengthen the existing ones.

It is high time to take the issue of quality in Ethiopian higher education more seriously and come up with practical solutions to avert the looming crisis. Otherwise, Ethiopia's grand plan to expand access to higher education will result in universities of poorer quality than those already in business.

DOI: http://dx.doi/org/ro.6oI7/ihe.20I7.90.9737

\section{Unusual in Growth and Composition: Ethiopian Private Higher Education}

\section{WONDWOSEN TAMrat AND DANIEL LeVy}

PROPHE (Program for Research on Private Higher Education) has a regular column in IHE. Wondwosen Tamrat is associate professor and founder-president of St. Mary's University, Ethiopia. E-mail:preswond@smuc.edu.et. Daniel Levy is SUNY Distinguished Professor, Department of Educational Policy a Leadership, University at Albany, US. E-mail:dlevy@albany.edu.

\section{Context}

With more than IIo,000 students (20I6), Ethiopia's private higher education (PHE) is the largest or second largest in sub-Saharan Africa. This large private presence exists despite Ethiopia being rather late to start PHE and despite some stiffly restrictive regulation.

It is common for expert and public opinion in a given country, partly for lack of knowledge of other countries, to hold an exaggerated view of how atypical their systems are. But a reasonable conclusion from scrutinizing Ethiopian PHE is that in fundamental ways it is indeed significantly atypical for sub-Saharan Africa. After acknowledging several not insignificant commonalities, we will hone in on the more striking differences.

Though large in absolute private enrollment, Ethiopia's I4-I7 percent private share is typical of sub-Saharan Africa. Furthermore, the types of Ethiopian PHE are those found throughout the region. By far the largest chunk is nonelite, 
which is some mix of demand-absorbing and more effective job-market oriented. Semielite and religious institutions are visible as well. The few semielite universities compete with the good public universities, especially in teaching and some other fields, and benefit from disorder in their public counterparts. Also, as seen elsewhere in the region, PHE's overwhelming majority of fields of study are market-oriented, but with some recent diversification into other fields. Women account for a larger share of the private than public sector. Myriad forms of community engagement are apparent. And both in Ethiopia and the region, while total enrollment growth has been very rapid in the private sector, it has been very rapid in the public sector as well, so that the private share has recently even slipped a bit.

Notwithstanding such similarities, atypical characteristics are more remarkable. One set of unusual characteristics concerns growth and regulation; another concerns the private sector's internal composition.

\section{Though large in absolute private enroll- ment, Ethiopia's 14-17 percent private share is typical of sub-Saharan Africa.}

\section{Atypical Growth and Regulation}

As African PHE emerges comparatively late in terms of global PHE and from low gross enrollment ratio (GER), so Ethiopian PHE is late (I998) for even the African context and started from an atypically low o.8 GER. Much of the reason for Ethiopia's late entry into PHE lay in the decades of repressive Marxist rule that followed the end of the long reign of Emperor Haile Selassie in I974 and banned all forms of private ownership. Yet today only Uganda may match Ethiopia in private enrollment. Meanwhile, Eritrea (which broke away from Ethiopia in I99I) remains one of the few countries in Africa or the world with no PHE.

Compared to most of the region, where the unplanned emergence and rapid growth of PHE caught governments by surprise, establishment with fast growth of PHE was rather planned and promoted by Ethiopia's post-Marxist government. Indeed the regulatory framework preceded the private education sectors emergence-and was mostly enabling (as opposed to restrictive) regulation.

Though it is common for African countries to promulgate "delayed regulation" when they see the academic and other weaknesses of easily proliferating private institutions, and common to impose some rules on the private sector not imposed on the public sector, in notable ways Ethiopia has gone to a regulatory extreme. Without legal war- rant, the government blocks private programs in law and teacher education. After PHE had played a pioneering role in Ethiopian distance education, it was temporarily banned from that realm, too. And while religious institutions often start within African private sectors and then thrive there, in Ethiopia the religious degrees offered by religious PHE are accepted only within religious society. They are not recognized by the state, a restrictive policy with job-market ramifications; to gain wider acceptance, programs would have to be secular and gain national accreditation.

\section{Atypical Composition of SUbSECTORS}

It is not by chance, then, that the religious subsector holds a markedly lower share of PHE than it does in most of the continent. Nor is it by chance that Ethiopia's religious subsector is mostly nonelite. Much of it was not created afresh but, rather, rose from preexisting schools at lower levels. In contrast, in many African countries religious institutions are among the strongest academic forces. Many former colonies had strong Catholic or Protestant roots to build upon in higher education, whereas Ethiopia was never colonized.

So if religious PHE is unusually small in Ethiopian PHE, what is unusually large? The answer is for-profit PHE. It accounts for the overwhelming majority of PHE. This is not just a difference between Ethiopian and most African PHE. It is a stunning difference. Not all African countries allow a for-profit presence and often the appearance of profit relates to legally nonprofit institutions finding ways to skirt regulatory restrictions. Moreover, in those countries with legal for-profits, the for-profits sit alongside an array of nonprofits. Not so in Ethiopia. It appears that the only nonprofit Ethiopian higher education institutions outside the (small) religious subsector are a few PHE institutions owned by NGOs. Among the for-profits, the bulk are private limited corporations, mostly family-owned. Forprofits are allowed at all tertiary education levels.

\section{Continuity vs. Change Going Forward}

Thus, in the face of a huge growth in demand for higher education in Ethiopia, a mix of enabling and restrictive policy has let PHE play a major role that is, however, limited in key respects. How will policy evolve as the country now faces not only continued growth, but a projected acceleration of it? If, as predicted, the total enrollment will nearly double over the next five years, with the private sector expected to receive an increasing share of this growth, policy choices about how supportively or restrictively to handle PHE will assume increasing importance. The private sector, bolstered by its relative success despite restrictive regulation, is confident that it could perform a larger role into the future, for a greater share of Ethiopia's enrollment, were government to provide stable and less antagonistic policy. 
Not all government policymakers share that view.

DOI: http://dx.doi/org/Io.6oI7/ihe.20I7.90.979I

\section{Uganda: Higher Education Modernization Needed}

\author{
Mukwanason A. Hyuha
}

Mukwanason A. Hyuha is emeritus professor of economics and consultant at Budembe Enterprises. E-mail: hyuhama@gmail.com.

Tn terms of quality, Uganda's education sector, modelled 1 on the basis of the British system, was one of the best in Africa until the early I990s. Thereafter, both the academic and physical infrastructures experienced serious declines in quality. Like in many other African countries, the higher education subsector in Uganda is currently facing various challenges-including, inter alia, underfunding across the board, inadequate academic staff at all levels, an acute shortage of senior staff, low remuneration packages for academic staff, inadequate facilities for graduate training, serious governance problems, low research output, scarcity of student scholarships, and suboptimal supervision of the sector by the mandated authorities. The main challenge is, however, underfunding.

Institutions of higher learning comprise 36 universities, four other degree-awarding institutions, and various certificate- and diploma-awarding institutions. The student population in these higher education institutions is just over 200,000 , of which 45 percent are women. These students represent about 2 percent of the entire population of learners in primary, secondary, and tertiary institutions in the country. In general, access to higher education by the poor is very problematic. Most of the students in these institutions come from well-to-do backgrounds. This is in contrast to access to primary and secondary education, which is broad and attainable by both rich and poor in general, in view of the ongoing universal primary and secondary education (UPE and USE) programs, implemented following the UN Declaration of September 2000. Further, many citizens of Kenya, Rwanda, Somalia, South Sudan, Tanzania, and other neighboring countries study in these institutions.

\section{Demand for Higher Education}

Since the mid-I980s, Uganda's higher education subsector has continued to register considerable growth in terms of institutions, primarily due to its high demand. Colleges of commerce and business studies dominate the subsector $(33$ percent), followed by universities (I 6 percent) and technical colleges (4 percent). Although Makerere University was the only degree-awarding institution in Uganda until I988, there are now 4I degree-awarding institutions in the country, of which II are public universities.

Overall, there is ample demand for university education, at least in the Eastern African region. This demand is far in excess of that for middle-level and technical education. This is a result of popular demand, intense advertising by universities, and the job market, which prefers degree holders to certificate and diploma holders. In addition, students who study science and technology have a better chance of being employed earlier, and more employment options, than those studying other disciplines. Consequently, most students, parents, and policy makers prefer university education to middle-level and technical education. This bias has led to a noticeable lack of middle-level technicians and workers, whom Uganda has to import. Hence, by 2016 ,

\section{Thereafter, both the academic and phys- ical infrastructures experienced serious declines in quality. Like in many other African countries, the higher education subsector in Uganda is currently facing various challenges}

less than ro percent of the training programs in health sciences and engineering were for diplomas. Needless to say, Uganda needs an immediate policy shift on this issue if it is to have the skilled labor needed to attract investment and propel economic growth and development.

Further, since the early I990s, there have been improvements in women's access to higher education, computer access and use, as well as enrollments in science and technology. The upsurge in enrollments has, however, been in business and computer-related disciplines, rather than in basic, mathematical, or other technical sciences. Factors to explain this include poor teaching facilities at secondary schools and underfunding, in addition to better employment opportunities in the articulated preferred areas. Due partly to the closing of technical institutes in favor of universities in the recent past, the production of middle-level technicians from technical institutions has, unfortunately, continued to decline.

The closing of lower-level tertiary training institutions was a retrogressive step, since middle-level technicians and artisans are indispensable in all construction and mainte- 